\title{
Analysis of the long-term agricultural drought onset, cessation, duration, frequency, severity and spatial extent using Vegetation Health Index (VHI) in Raya and its environs, Northern Ethiopia
}

Eskinder Gidey ${ }^{1,2,3^{*}}$, Oagile Dikinya ${ }^{1}$, Reuben Sebego ${ }^{1}$, Eagilwe Segosebe ${ }^{1}$ and Amanuel Zenebe ${ }^{2,3}$

\begin{abstract}
Background: Droughts cause serious effects on the agricultural and agro-pastoral sector due to its heavy dependence on rainfall. Several studies on agricultural drought monitoring have been conducted in Africa in general and Ethiopia in particular. However, these studies were carried out using the limited capacity of drought indices such as Normalized Difference Vegetation Index (NDVI), Vegetation Condition Index (VCI), and Deviation of Normalized Difference Vegetation Index (DevNDVI) only. To overcome this challenge, the present study aims to analyze the long-term agricultural drought onset, cessation, duration, frequency, severity and its spatial extents based on remote sensing data using the Vegetation Health Index (VHI) 3-month time-scale in Raya and its surrounding area, Northern Ethiopia. Both the MOD11A2 Terra Land Surface Temperature (LST) and eMODIS NDVI at 250 by $250 \mathrm{~m}$ spatial resolution and hybrid TAMSAT monthly rainfall data were used. A simple linear regression model was also applied to examine how the agricultural drought responds to the rainfall variability.

Results: Extremely low mean NDVI value ranged from 0.23 to 0.27 was observed in the lowland area than mid and highlands. NDVI coverage during the main rainy season decreased by $3-4 \%$ in all districts of the study area, while LST shows a significant increase by $0.52-1.08^{\circ} \mathrm{C}$. VHI and rainfall value was significantly decreased during the main rainy season. Agricultural drought responded positively to seasonal rainfall $\left(R^{2}=0.357\right.$ to $\left.R^{2}=0.651\right)$ at $p<0.01$ and $p<0.05$ significance level. This relationship revealed that when rainfall increases, $\mathrm{VHI}$ also tends to increase. As a result, the event of agricultural drought diminished.

Conclusions: Remote sensing and GIS-based agricultural drought can be better monitored by VHI composed of LST, $\mathrm{NDVI}, \mathrm{VCl}$, and TCl drought indices. Agricultural drought occurs once in every 1.36-7.5 years during the main rainy season, but the frequency, duration and severity are higher (10-11 times) in the lowland area than the mid and highlands area (2-6 times) during the last 15 years. This study suggests that the effect of drought could be reduced through involving the smallholder farmers in a wide range of on and off-farm practices. This study may help to improve the existing agricultural drought monitoring systems carried out in Africa in general and Ethiopia in particular. It also supports the formulation and implementation of drought coping and mitigation measures in the study area.
\end{abstract}

Keywords: Agricultural drought, LST, VCI, NDVI, TCI, Rainfall, VHI, Remote sensing, GIS, Raya, Ethiopia

\footnotetext{
*Correspondence: eskinder14@yahoo.com

1 Department of Environmental Science, University of Botswana, Private

Bag UB 0704, Gaborone, Botswana

Full list of author information is available at the end of the article
} 


\section{Background}

In arid and semi-arid regions, rain-fed agricultural production is mostly a risky practice because of its high sensitivity to climate extremes, including drought (Lei et al. 2016; Choi et al. 2013). Several studies have indicated that drought causes a significant decline in agricultural production and productivity all over the world. This can occur with no warning, without recognizing borders or economic and political differences (Kogan 2000). For instance, during the periods of 2001-2012, moderateto-exceptional (ME), severe-to-exceptional (SE) and extreme-to-exceptional (EE) droughts covered about $17-35 \%, 7-15 \%$ and $2-6 \%$ of the total land mass of the world, respectively (Kogan et al. 2013). For example, the droughts of 2010 in Russia and 2011/12 in the USA produced considerable local and global economic impacts (Kogan et al. 2016). As a result, the balance of food supply and demand was significantly affected due to severe droughts at local, regional, and global scales (Van Hoolst et al. 2016; Song et al. 2004). In dry areas, where the rainfall pattern is highly variable, the most susceptible shock is realized (Maybank et al. 1995). Several regions of the world, particularly the main grain-growing countries (e.g., USA, China, Russia, India, and European Union) are thus experiencing an increase in the frequency and intensity of droughts incidence (Kogan et al. 2016; Owrangi et al. 2011).

In developed countries, drought monitoring and early warning systems are based on earth observation products and it is highly effective, while in the majority of African countries (including Ethiopia) the situation largely depends on the in-situ climate data only, which significantly affects the smallholder farmers. It also lacks the continuous spatial coverage needed to characterize and monitor the detailed spatial pattern of drought conditions (Gu et al. 2007). For instance, drought is a persistent problem in Botswana (Segosebe 1990) and other African countries. Efforts have been made to set up regional drought monitoring in the Southern African Development Community (SADC), the Great Horn of Africa (GHA), and the West African Permanent Interstate Committee on Drought Control in the Sahel (CILSS). All these monitoring systems are confined only to the selected regions and hence, they do not include the entire African countries and their initiatives are ineffective in majority part of the continent in providing provide real-time information on the past and future drought events (Vicente-Serrano et al. 2012). Vicente-Serrano et al. (2012) reported that many droughts affected developing countries, including Ethiopia, facing difficulties in monitoring droughts due to weak institutional structures, lack of technical capacity, limited progress in mobilizing stakeholder involvement and investment, and lack of in-depth understanding of the benefits of effective drought management for poverty alleviation and economic development and the lack of a preparedness culture. The drought has thus remained a bottleneck problem in the area. For instance, during the 1981-1984, several countries in the continent were under the spell of catastrophic drought events.

Ethiopia is one of the countries with frequent drought events due to poor and erratic rainfall availability where the problem is severe in the northern parts. Sholihah et al. (2016) reported that the incidence of El Nino phenomenon droughts has also been frequently occurring over the decades triggering several threats to the agriculture sector. Particularly, the arid and semi-arid area has been severely affected by the recurrent droughts. The cessation, duration, frequency, severity and spatial extent of agricultural drought in the area is high. Although, substantial growth in the major crop types (e.g., teff, barley, maize, wheat, and sorghum and others) were observed in terms of productivity and area coverage, yields are low when evaluated by international standards. This is because production is highly susceptible to weather shocks, particularly droughts (Se et al. 2011). Agricultural production, mainly in the poor area has remained highly dependent on the weather (Zhang et al. 2016). The challenges may also arise in the future as the natural resources largely over exploited due to rapid population growth. Vicente-Serrano et al. (2012) stated that the current population projections in the area also significantly increased in the regions where the area intermittently affected by the persistent water shortage leading to catastrophic drought. Umran Komuscu (1999) revealed that drought impacts are usually first apparent in agriculture, but gradually move to other water-dependent sectors. The agricultural drought was, therefore, occurring due to unfavorable precipitation. Agriculture is the first sector affected by the hydro-meteorological droughts because it adversely affects the growth of vegetation as well as crop production (Bhuiyan et al. 2006), but later moves to other water dependent sectors (Umran Komuscu 1999).

Agricultural drought is primarily expressed by the reduction of crop production and/or productivity due to erratic rainfall as well as insufficient soil moisture in the crop root zones (Sruthi and Aslam 2015; Alemaw and Simalenga 2015). However, the reliance on weather data alone is not adequate to monitor an area of drought, particularly when these data are untimely, sparse, and incomplete (Peters et al. 2002). The conventional ways of drought monitoring which depend only on weather stations (e.g., Ethiopia) lack continual spatial coverage to characterize and monitor the spatial pattern of drought incidences in depth (Gu et al. 2007). 
Kogan (2000) reported that the recent advances in satellite technology improved the ability to monitor droughts. Remote sensing and GIS-based agricultural drought monitoring has thus attracted interest of various scientists such as agriculturalists, hydrologists, meteorologists, and environmentalists because it provides more accurate, flexible and reliable findings (e.g., spatio-temporal trends of drought) in drought studies. Seiler et al. (1998) noted that reliable, satellite-based drought indices are credible in detecting the spatial and temporal drought occurrence, which is highly important for conducting effective drought monitoring, and for alleviating the risk arises from drought. Likewise, those satellite observation products can complement the information gathered by traditional and ground-based drought assessment techniques that rely only on meteorological observations. However, it requires timely information about vegetation condition related to drought, flooding, or fire danger (Brown et al. 2015). This method of drought monitoring is feasible, highly accurate and cost-effective to assess large areas with different time-scale. It also provides realtime and dynamic information for terrestrial ecosystems, facilitating effective drought monitoring (Zhang et al. 2016). Bhuiyan (2004) stated that agricultural droughts reflect vegetation stress. Assessing the vegetation health status of a given area is paramount significant to characterize the incidence of agricultural drought, but it requires at least 10 years of satellite observation data and suitable drought index. Furthermore, the understanding, monitoring, and mitigating drought are becoming a very difficult task because of the intrinsic nature of the phenomenon (Vicente-Serrano et al. 2012). However, satellite observations overcome some limitations of station-based meteorological observations, providing the potential for cost-effective, spatially explicit and dynamic large-scale drought monitoring (Zhang et al. 2016). Likewise, satellite observation products (e.g., eMODIS NDVI, MOD11A2 LST) supported with advanced remote sensing drought indices such as Vegetation Health Index (VHI) can help to assess the incidence of agricultural droughts. Liu and Kogan (1996) stated that the seasonal and/or inter-annual droughts can be delineated by using the Vegetation Condition Index (VCI) and Temperature Condition Index (TCI) because both indices can help to generate VHI. Rhee et al. (2010) reported additional drought indices such as the Normalized Difference Drought Index (NDDI), the Normalized Difference Water Index (NDWI), and the Normalized Multiband Drought Index (NMDI) were introduced based on hyperspectral remote sensing data. These drought indices might be significant, but VHI has been the popular agricultural drought index. However, it requires both NDVI and LST data (Zhang et al. 2017; Choi et al. 2013).
Agricultural drought monitoring using VHI is therefore essential to provide reliable information. Studies showed that (e.g., Kogan and Guo 2016) the incident of droughts has continued with a significant agricultural production reduction or loss and other associated impacts such as malnutrition, human health deterioration, depletion of water resources, rising of food prices, population migration, and mortality. Therefore, there is a need to obtain synoptic information on a recurring and timely basis, drought-affected agricultural zones to identify area requiring immediate attention (Van Hoolst et al. 2016) and to mitigate the implication. In this study, the agricultural drought monitoring was conducted in 3-month time-scale (i.e., July-September). The specified time-scale is vegetation as well as the crop gestation period during the main rainy season. Similarly, Zhang et al. (2017) studied the drought phenomenon during vegetation growing seasons in the United States. Therefore, studying agricultural drought during the vegetative phase can provide better drought characteristics information. The novelty of this study is that it conducted VHI based long term agricultural drought monitoring in Africa in general and Ethiopia in particular. The objective of this study was to analyze the long-term agricultural drought onset, cessation, duration, frequency, severity, and its spatial extent using the VHI that integrates NDVI, VCI, LST and TCI in Raya and its surrounding area, Northern Ethiopia. The study is decisive for monitoring, understanding and managing the incidence of agricultural droughts through satellite earth observation data.

\section{Methods}

\section{Study area}

This study was undertaken in Raya and its environs (Northern Ethiopia) which is an intermountain plain area located at $39^{\circ} 24^{\prime} 40^{\prime \prime}$ and $40^{\circ} 25^{\prime} 20^{\prime \prime}$ longitude Easting and $12^{\circ} 7^{\prime} 20^{\prime \prime}$ and $13^{\circ} 8^{\prime} 0^{\prime \prime}$ latitude Northing (Fig. 1) (Gidey et al. 2017). It consists of 11 districts, namely Megale, Yalo, Gulina, Gidan, Kobo, Alaje, Alamata, Hintalo Wejirat, Ofla, Endamehoni, and Raya Azebo. The total area coverage of the study area is estimated at $14,532 \mathrm{~km}^{2}$ of which (48\%) falls in the southern Tigray region, $22 \%$ in Amhara and (30\%) in the Afar region (Gidey et al. 2017). The area receives up to $558 \mathrm{~mm}$ of rainfall annually (Gidey et al. 2017). Rainfall is erratic and bimodal (Ayenew et al. 2013). In 2015, the highest temperature was observed since 1984. During this time, the maximum temperature (Tmax) and minimum temperature (Tmin) were 30.5 and $15.9{ }^{\circ} \mathrm{C}$, respectively. The study area consists of four river basins such as Denakil basin, which covers about 10,265.8 $\mathrm{km}^{2}$ (70.64\%), Lake Ashinge $16.0 \mathrm{~km}^{2}$ (0.11\%), Abay (Blue Nile) $13.2 \mathrm{~km}^{2}(0.09 \%)$, and Tekeze $4237.0 \mathrm{~km}^{2}(29.16 \%)$. The mean elevation value of the 


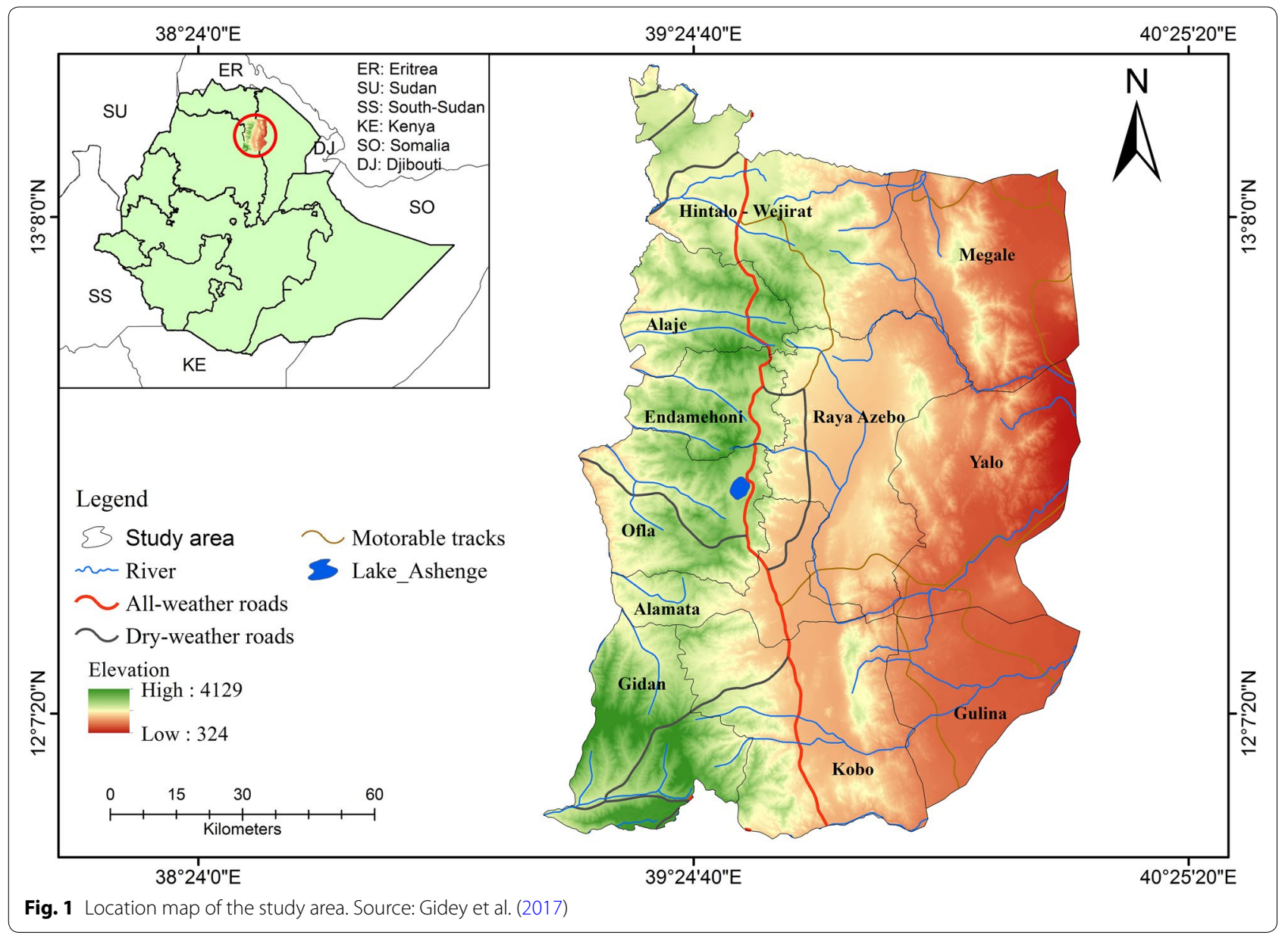

area is 1762 meters above sea level (m.a.s.l) (Gidey et al. 2017). Similarly, the slope of the study ranged from $0 \%$ (flat) to $395.3 \%$ (very steep slope). The soils of the study area i.e., eutric cambisols are the predominant soil type in the area covering about $4667.1 \mathrm{~km}^{2}$ or $32.1 \%$, while dystric gleysols cover only small portions of the site, i.e., nearly $1.1 \mathrm{~km}^{2}$ or $0.001 \%$, respectively (Gidey et al. 2017). The prominent land cover type is deciduous woodland which covers nearly $6097.6 \mathrm{~km}^{2}(42.0 \%)$, while others e.g., Croplands cover $3362.2 \mathrm{~km}^{2}(23.1 \%)$, open grassland with sparse shrubs $1517.4 \mathrm{~km}^{2}$ (10.4\%), deciduous shrub land with sparse tree $1298.1 \mathrm{~km}^{2}(8.9 \%)$, sparse grassland $789.9 \mathrm{~km}^{2}$ (5.4\%), croplands with open woody vegetation $503.5 \mathrm{~km}^{2}(3.5 \%)$, Bare soil $409.6 \mathrm{~km}^{2}(2.8 \%)$, open grassland $202.3 \mathrm{~km}^{2}(1.4 \%)$, closed grassland $197.0 \mathrm{~km}^{2}(1.4 \%)$, mosaic forest/savanna $129.2 \mathrm{~km}^{2}(0.9 \%)$, montane evergreen forest $14.5 \mathrm{~km}^{2}(0.1 \%)$ and water bodies $11.1 \mathrm{~km}^{2}$ (0.1\%), respectively. According to the Raya Valley Livelihood Zone report (2007), the dominant crop types in the study area are sorghum, teff, and maize. Of all crops, sorghum and maize are widely used as a staple food by the community, while teff (Eragrostis tef) is largely produced for both cash and food crops to improve their livelihoods. In the study area, the smallholder farmers prepare their lands during the months of May and June because JulySeptember are main rainy season.

\section{Data acquisition Expedited MODIS (eMODIS)-TERRA NDVI}

Tsiros et al. (2004) reported that the earth observation data could effectively be used to monitor drought onset, cessation and the vegetation's response to drought. In this study, the agricultural drought condition of the study area was investigated using the real-time and historical EROS Moderate Resolution Imaging Spectroradiometer Earth observation products. A multi-temporal smoothed monthly Terra expedited Moderate Resolution Imaging Spectoradiometer Normalized Difference Vegetation Index (eMODIS-NDVI) data from the period of 2001 to 2015 at $250 \mathrm{~m}$ spatial resolution were acquired from the Famine Early Warning Systems Network (FEWS NET) East-Africa region. The Terra eMODIS-NDVI data are better for agricultural drought monitoring than Aqua. The main reason is that the Aqua eMODIS data 
are more prone to noise than the Terra data, likely due to differences in the internal cloud mask used in MOD/ MYD09Q1 or composting rules (Brown et al. 2015).

\section{Land Surface Temperature (LST)}

In this study, the MOD11A2 LST and Emissivity Terra 8-day temporal resolution (later aggregated into monthly bases) data were obtained from the National Aeronautics and Space Administration (NASA) - United States Geological Survey (USGS) Land Process Distributed Active Archive Center (LP DAAC). The ultimate reasons to use the daytime (Terra) LST data were its temporal evolution. Frey et al. (2012) reported that the temporal evolution of LST acquired during the daytime is better to get in-depth information than the Aqua (night-time) because a significant change in LST change can be observed during the nighttime. However, in the nighttime (Aqua), LST largely remains stable; as a result, the restriction on time differences could be relaxed. The MODIS LST introduces a higher quality of LST data than AVHRR sensor due to its temporal and spatial variations and up-to-date algorithm such as time of acquisition, satellite view zenith and azimuth angle, quality flags for easy interpretation of the products (Frey et al. 2012). A total of 169 MOD11A2 LST (morning overpass or Terra) data product collection of 005 used to assess the LST condition of the study area from the period of 2001-2015. The daytime or Terra temperature of vegetation canopy is an essential characteristic (Kogan and Guo 2016). This data was used as an input to compute the TCI and VHI, which is an advanced and integrated agricultural drought-monitoring model.

\section{Precipitation}

Precipitation data are an extremely useful meteorological parameter in drought studies. In this study, the longterm monthly precipitation data were collected from the National Meteorological Agency of Ethiopia for the period 2001-2015. The data were mainly used to investigate the response of agricultural drought to rainfall.

\section{Data processing and analysis Expedited MODIS (eMODIS)-TERRA NDVI}

eMODIS is a process for creating a community-specific suite of vegetation monitoring products based on the National Aeronautics and Space Administration's (NASA) Earth Observing System (EOS) Moderate Resolution Imaging Spectroradiometer (MODIS) and produced in the U.S. Geological Survey's (USGS) Earth Resources Observation and Science (EROS) Center (Jenkerson and Schmidt 2008). Jenkerson et al. (2010) reported that the eMODIS NDVI data are well suited for vegetation studies because the data were acquired with a frequent and repeated cycle. Besides, the same author stated that the spatial resolutions of the data were better than the Advanced Very High Resolution Spectroradiometer (AVHRR) and SPOT-Vegetation products. Rhee et al. (2010) reported that the Normalized Difference Vegetation Index (NDVI) has been most widely used for drought monitoring. However, NDVI data alone cannot fully show the severity and magnitude of droughts (Kogan et al. 2013; Kogan and Guo 2016). Therefore, the multi-temporal analysis of eMODIS NDVI data supported by VCI and TCI can significantly improve the drought monitoring and early warning systems. Barbosa et al. (2006) reported that the satellite derived NDVI can be computed based on the red, which has low reflectance value and NIR high reflectance, portions of the wavelength. Predominantly, in non-drought periods, green and vigorous vegetation reflects little light in the visible (VIS) spectrum due to high light absorption by chlorophyll and much reflection in the near-infrared (NIR) part due to the specificity of light scattering by leaf internal tissues and water content (Kogan and Guo 2016). In this case, the healthy vegetation is strongly absorbed the visible incident solar (red) and it reflects less solar radiation in the visible spectrum. However, the unhealthy vegetation strongly reflects the near-infrared light. Hence, healthy and dense vegetation has the highest NDVI value typically $>0.5$ than the unhealthy. Furthermore, the main reason to use eMODIS NDVI data in this study was that the eMODIS Terra data are corrected from molecular scattering, ozone absorption, and aerosols. Likewise, the eMODIS NDVI is good to measure the density of chlorophyll contained in vegetative cover (Swets 1999). Kogan (1995) revealed that NDVI data helps to assess the VCI development reflects both temperatures and precipitation conditions. The NDVI was mathematically computed as follows (Eq. 1):

$$
N D V I=(N I R-R E D) /(N I R+R E D)
$$

where NIR $=$ near-infrared reflectance and $\mathrm{RED}=$ visiblered reflectance.

In this study, the row eMODIS data were processed, rescaled and analyzed in ArcGIS 10.4.1 package to find out the real NDVI value of the study area as follows (Eq. 2):

$$
\begin{aligned}
& \text { eMODIS NDVI } \\
& =\text { Float (Smoothed eMODIS NDVI - 100) / } 100
\end{aligned}
$$

The value of eMODIS NDVI ranges from -1.0 to +1.0. The standard unit of eMODIS NDVI is NDVI ratio. The negative NDVI ratio shows less vigorous or unhealthy vegetation cover mainly occurred in a barren rock (rock outcrop), and sand, while the positive NDVI value depicts the healthy vegetation cover. NDVI values are much higher in healthy and dense vegetation than 
rocks, water, and bare soil (Kogan 1995). Similarly, sparse vegetation cover such as grasslands, bushes/shrubs may result in moderate NDVI values range from 0.2 to 0.5 . High NDVI values (0.6-0.9) correspond with dense vegetation in the temperate and tropical forests or crops at their peak growth stage. The NDVI is thus a very good parameter for studying vegetation greenness, and mapping vegetation health or cover dynamics status in each satellite image pixel. In this study, the eMODIS NDVI data were used as input to compute the VCI only.

\section{Vegetation Condition Index (VCI)}

Several drought indices have been developed for assessing the drought characteristics such as intensity, duration, severity and spatial extent (Mishra, and Singh 2011) (e.g., VCI). The VCI which is derived from remote-sensing data has been used naturally allied with vegetation state and cover (Karnieli et al. 2010). The index is highly applicable for assessing the vegetation stress and/or to examine the response of vegetation. VCI quantifies the weather component (Singh et al. 2003) and portray precipitation dynamics as compared to the NDVI (Kogan 1990). This index helps to show the cumulative environmental impact on vegetation (Singh et al. 2003). The VCI permits not only the description of vegetation but also an estimation of spatial and temporal vegetation changes and weather impacts on vegetation (Kogan 1990). In this study, the smoothed monthly eMODIS NDVI data were used as input to compute the VCI model. Kogan (1995) pointed out that VCI has an excellent capability to identify drought and measure its time of onset, intensity, duration, and impact on vegetation. In this study, the VCI model was applied to examine the agricultural drought status of the study area as follows (Eq. 3):

$V C I=100 \times\left(N D V I_{i}-N D V I_{\min }\right) /\left(N D V I_{\max }-N D V I_{\min }\right)$

where $\mathrm{NDVI}_{\mathrm{i}}=$ the current smoothed NDVI value of $\mathrm{i}^{\text {th }}$ month, $\mathrm{NDVI}_{\text {min }}$, and $\mathrm{NDVI}_{\max }$, is a multi-year (20012015) absolute minimum and maximum NDVI value for every pixel at a particular period.

Vegetation Condition Index values show how much the vegetation has advanced or deteriorated in response to weather. According to Kogan (1995), the value of VCI is measured in percentile ranged from 0 to 100 . A high value of VCI signifies healthy and/or unstressed vegetation condition. It is thus the area is free of the agricultural drought incidence. The VCI value of $50-100 \%$ shows above normal or wet condition. This means that there is no drought, while values between 35 and 50 percent show area under the incidence of moderate drought (MD) and VCI value between 20 and 35 percent shows severe drought (SD) prevalence. Furthermore, the seasonal and/or annual $\mathrm{VCI}$ value $0-20 \%$ is showing very severe agricultural drought event (VSD). However, in some cases, VCI model based on NDVI alone is not sufficient for agricultural drought monitoring (Kogan 1995; Sholihah et al. 2016). Hence, the combination of both VCI and TCI derived from MOD11A2 LST Terra data are significant to assess agricultural droughts. This study, therefore, applied VHI to analyze the long-term agricultural drought onset, cessation, duration, frequency, severity and its spatial extents.

\section{Temperature Condition Index (TCI)}

Land Surface Temperature (LST) Land Surface Temperature (LST) described as the radiative skin temperature of the land derived from solar radiation. ${ }^{1}$ This data used as an indicator of the energy balance at the Earth's surface and the so-called greenhouse effect in climate change studies (Frey et al. 2012). The MOD11A2 Terra v.005 LST and emissivity measures the ground temperature of the earth's surface. This helps to assess the overall vegetation health, soil moisture status and impact of thermal (Parviz 2016; Karnieli et al. 2010). In this study, the MOD11A2 Terra 8 days LST data initially acquired at a $1 \mathrm{~km}$ spatial resolution archived in Hierarchical Data Format-Earth Observing System (HDF-EOS). However, the MODIS Re-projection Tool (MRT) v 4.1 developed on March 2011 was applied to resample the $1 \mathrm{~km}$ MOD11A2 LST data in 250-m spatial resolution together with the eMODIS NDVI data. The MRT also used to convert the Hierarchical Data Format (HDF) into a GeoTIFF image format to carry out better analysis and interpretations on the MOD11A2 LST and eMODIS NDVI. In addition, the MRT tool was used to reproject the data from its Sinusoidal Projection type into Universal Transverse Mercator (UTM) projection zone 37 as the dominant part of Ethiopia relies on this projection type. The values of the MOD11A2 Terra LST data were computed by averaging all the valid pixels under clear-sky. The valid LST value ranges from 7500 to 65,535 (Wan 2006) and it was rescaled by 0.02 to get the correct LST value in Kelvin unit. Hence, the values of LST will be from 150 to 1310.7 Kelvin. In this study, the LST data were rescaled and converted into ${ }^{\circ} \mathrm{C}$ (degree Celsius) unit as follows (Eq. 4):

$$
\mathrm{LST}=(\varpi \times 0.02)-273.15
$$

where LST $=$ Land Surface Temperature in Degree Celsius $\left({ }^{\circ} \mathrm{C}\right), \varpi=$ Row Scientific data (SDS).

The TCI is a thermal stress indicator used to determine temperature related drought situations. This satellitederived index assumes that during the drought event soil

\footnotetext{
${ }^{1}$ http://lst.nilu.no/language/en-US/Home.aspx.
} 
moisture diminished significantly and cause high vegetation stress. Kogan (1995) noted that computation of the TCI model is more likely similar to the VCI. However, the model has considerably improved to assess the response of vegetation to temperature. The TCI assumed that higher temperature has a tendency to cause deterioration or drought during the vegetative growth period, while low temperatures are largely favorable to vegetation during its development. Hence, low TCI values correspond with vegetation stress due to dryness or harsh weather by high-temperature condition (Karnieli et al. 2006; Bhuiyan 2004). The TCI was estimated using the following mathematical expression (Eq. 5):

$T C I=100 \times\left(L S T_{\max }-L S T_{i}\right) /\left(L S T_{\max }-L S T_{\min }\right)$

where $\mathrm{LST}_{\mathrm{i}}=\mathrm{LST}$ value of ith-month, $\mathrm{LST}_{\max }$ and $\mathrm{LST}_{\min }$ are the smoothed multi-year maximum and minimum LST.

\section{Vegetation Health Index (VHI)}

Rhee et al. (2010) reported that the recently developed drought indices (e.g., NMDI, NDWI, and NDDI) did not perform significantly better than NDVI with $1 \mathrm{~km}$ resolution in the arid region. Studies showed NDVI only is not capable to depict drought or non drought conditions. The VHI model has been found to be a robust agricultural drought-monitoring index and it has good efficiency to explore the spatial extent of agricultural severity drought. In the arid region, VHI was quite highly correlated with in-situ variables (Rhee et al. 2010). Karnieli et al. (2006) stated that the VHI was applied only in arid, semi-arid and sub humid climatic regions where water is the main limiting factor for vegetation growth. VHI is dependent on the weather and ecological conditions of the region (Singh et al. 2003). Seiler et al. (1998) reveal that the VHI combination of TCI and VCI is essential to characterize the spatial extent, the magnitude, and severity of agricultural droughts in a good agreement with precipitation patterns. Likewise, they are paramount significant to examine the effect of weather on vegetation and to exemplify the condition of crop development. Furthermore, both the VCI and TCI indices have used for estimation of vegetation health and drought monitoring (Singh et al. 2003; Jain et al. 2009). Hence, the vegetation stress due to dry and wetness condition was assessed to investigate the severity of agricultural droughts in the study area. Tsiros et al. (2004) and Parviz (2016) reported that the combination of both VCI and TCI the so-called VHI has shown satisfactory results in several parts of the globe when it is used for drought detection, assessment of weather impact and/or evaluation of vegetation condition. The VHI show the availability of moisture and temperature or thermal condition in vegetation (Kogan 2001). This drought index has better performance for agricultural drought monitoring (Parviz 2016). Marufah et al. (2017) reported that VHI used to understand the duration, spatial distribution, and severity or category of agricultural drought. Studies showed that low VCI and TCI values or warm weather largely signifies stressed vegetation conditions and the prevalence of agricultural droughts. In this study, both the VCI and TCI components given an equal weight due to the reason that moisture and temperature contribution during the vegetative growth period not yet known (Kogan 2001). Similarly, Karnieli et al. (2006) reported that due to a lack of more accurate information on the influence of VCI and TCI on the VHI in Mongolia, the coefficient of the VHI equation was fixed at 0.5.

The VHI was mathematically computed as follows (Fig. 2) (Eq. 6):

$$
V H I=a \times V C I+(1-a) \times T C I
$$

where $\mathrm{VHI}=$ Vegetation Health Index, $a=0.5$ (contribution of $\mathrm{VCI}$ and $\mathrm{TCI}$ ), $\mathrm{VCI}=$ Vegetation Condition Index, $\mathrm{TCI}=$ Temperature Condition Index.

Drought warning issued if the VHI values decrease below 40 (Kogan et al. 2013). The lower VHI indicated that the high incidence of drought whereas a higher VHI value show that wet or non-drought conditions (Table 1).

This study analyzed the onset, cessation, duration, and recurrence interval of agricultural drought. Studies showed that agricultural drought is striking when the VHI value is below 40 and ends if the values exceed 40 (Table 1). The agricultural drought duration of this study was also analyzed by the number of consecutive drought periods, i.e., the time-period between the onset and the end of the drought.

\section{Coefficient of variation (CV) analysis}

The coefficient of variation (CV) analyses was conducted to examine the seasonal VHI variability relative to the mean percent from the periods of 2001-2015. The coefficient of variation statistically computed as follows (Eq. 7):

$$
C V(\%)=100 \times \frac{\sigma}{\bar{x}}
$$

where $C V(\%)=$ Coefficient of variation of VHI in percentage, $\sigma=$ Standard deviation of VHI, $\bar{x}=$ long-term mean of VHI.

\section{Regression analysis between VHI and rainfall}

In this study, a regression analysis was carried out between agricultural drought as derived from VHI and rainfall only because there is no long-term record of crop yield data in the study area. Wilhite and Glantz (1985) 


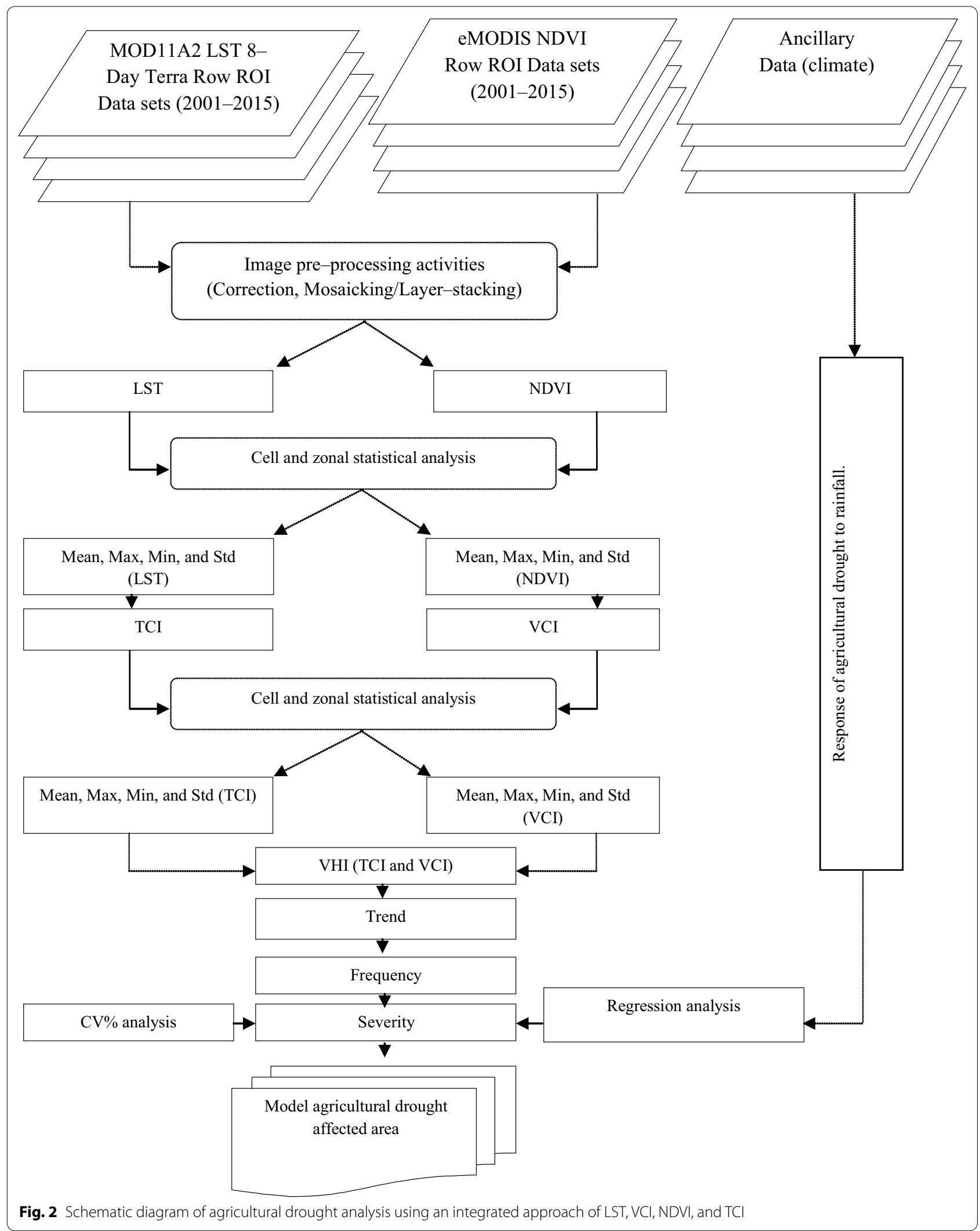


Table 1 Agricultural drought severity by VHI (Source: Kogan 2001)

\begin{tabular}{ll}
\hline Level of severity & VHI values \\
\hline Extreme drought & $<10$ \\
Severe drought & $10-20$ \\
Moderate drought & 200 \\
Mild drought & $30-40$ \\
No drought & $>40$ \\
\hline
\end{tabular}

reported that drought can occur in both high as well as low rainfall area. Therefore, it is useful to evaluate how the agricultural drought responded to rainfall because there is high rainfall variability in Raya and its environs. The regression analysis was conducted as follows (Eq. 8):

$$
Y_{i}=\beta_{0}+\beta_{1} X_{i}+\varepsilon_{i}
$$

where $Y_{i}=\mathrm{VHI}$ for the ith period, $X_{i}=$ seasonal rainfall, $\beta_{0}+\beta_{1} X_{i}=$ linear relationships between the independent and dependent variables, $\beta_{0}=$ Mean of $Y_{i}$ when $X_{i}$ $=0$ (intercept), $\beta_{1}=$ Change in the mean of $Y_{i}$ when $X_{i}$ increases by 1 (slope), $\varepsilon_{i}=$ Random error term.

\section{Results and discussion}

\section{Long-term agricultural drought analysis}

Figure 3 shows the multi-temporal trend of LST-NDVI, VCI-TCI, and VHI-rainfall for the period 2001 to 2015. The lowland area presented in Fig. 3a1-c1 reveals that the mean NDVI value was between 0.23 and 0.27 and this sparse NDVI value is extremely low when it is evaluated by scientifically accepted thresholds, while the LST was high and it ranges between 39.6 and $41.29^{\circ} \mathrm{C}$. Therefore, low NDVI values are mostly reached at high LST values because the vegetation is under high water stress. In the midland area shown in Figs. 3d1-f1 and 4a1 relatively better NDVI value ranged between 0.44 and 0.57 was observed, while the LST was between 30.3 and $34.97^{\circ} \mathrm{C}$. In this area, the LST value was relatively lower than the lowland area stated in Fig. 3a1-c1, but it is still an unfavorable condition for the vegetation high moisture stress. In the highlands area, good NDVI coverage ranges between 0.53 and 0.57 was observed. Besides, low LST value ranges between 22.85 and $24.6{ }^{\circ} \mathrm{C}$ was observed in the same area. High LST during the vegetation growing period may cause vegetation stress. Hence, the increase in surface temperature may significantly influence vegetation development (Karnieli et al. 2006). Singh et al. (2003) reported that NDVI becomes an important tool for vegetation cover and/or growth analysis. Generally, this study observed that NDVI coverage during the main rainy season decreased by $3-4 \%$ in all districts of the study area. However, the LST shows a significant increase by $0.52-1.08{ }^{\circ} \mathrm{C}$ across all agro-ecologies as well as districts in the last 15 years (Fig. 5). The increase in LST and the decrease in NDVI contribute considerable moisture stress that can trigger the incidences of agricultural drought. Furthermore, Figs. 3a2-f2 and 4a2-e2 show the trend of VCI and TCI. The results showed that the stress of vegetation was due to rising surface temperature. In the lowland area, the values of VCI were between 37.18 and 44.48 , while TCI was largely between 38.54 and 39.58. In the midland area, the values of VCI were between 53.77 and 62.65 , while TCI was 52.57-64.4. In the highland area, the VCI value ranged between 63.94 and 67.87 , while TCI was 66.63-68.88.

Furthermore, Figs. 3a3-f3 and $4 \mathrm{a} 3-\mathrm{e} 3$ indicated that $\mathrm{VHI}$ and rainfall value was significantly diminished during the main rainy season. This revealed that the incidence of agricultural drought became more frequent and severe because it is more sensitive to soil moisture, particularly the lowland and some parts of mid and highland area was seriously affected. For instance, the VHI value of the lowland area was between 38.38 and 40.55, while rainfall was about 274.42-379.87. In the midland area, better VHI values were observed ranged from 53.1762.82. Moreover, in the highland area, the VHI value ranged between 66.47 and 70.65 was observed. Bhuiyan (2008) reported that during 1985 and 1986 monsoon season, VHI showed severe to extreme droughts in the western and some northern parts of Thar Desert, India. In the same region, mild to moderate droughts severity were also observed in the rest of the country. Moreover, the validity of the VHI as a drought detection index relies on the assumption that NDVI and LST at a given pixel will vary inversely over time, with variations in $\mathrm{VCI}$ and $\mathrm{TCI}$ driven by local moisture conditions (Karnieli et al. 2010).

\section{Agricultural drought onset, cessation, duration, and recurrence interval analysis}

Table 2 shows the seasonal agricultural drought onset, cessation, duration, and recurrence interval. The results reveal that agricultural drought occurred in a different time-period, duration and recurrence interval. It strikes all districts once in every $1.36-7.5$ years during the main rainy season. Serious drought conditions during the crop growing season eventually affect crop yield (Rhee et al. 2010). For example, the districts of Yalo and Gulina were hit by the agricultural drought that started in 2004 and ends in 2009. This incidence was affecting the livelihood of the community for about 6 years and it was recorded as the highest drought period during the last 15 years (Table 2). Similarly, another drought event which covers the larger portion of the area was started in 2011 and ends in 2015. The duration of this drought event was 


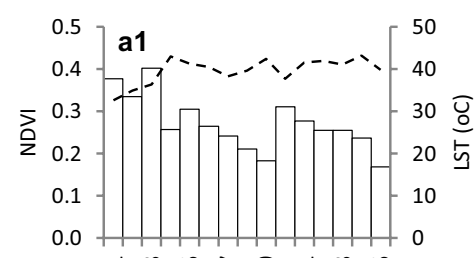

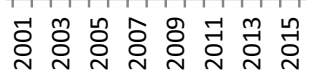
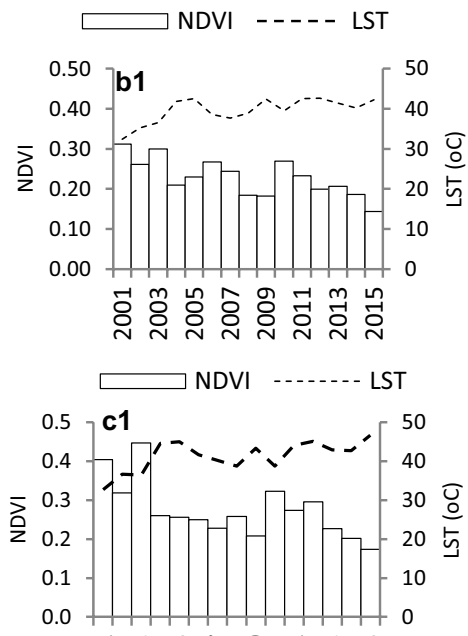

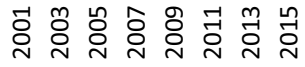

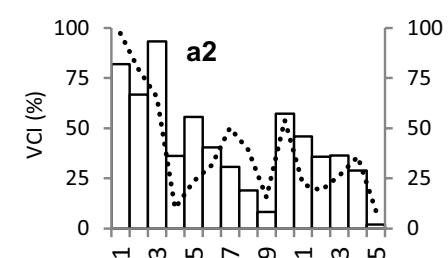

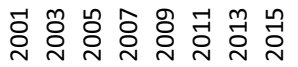
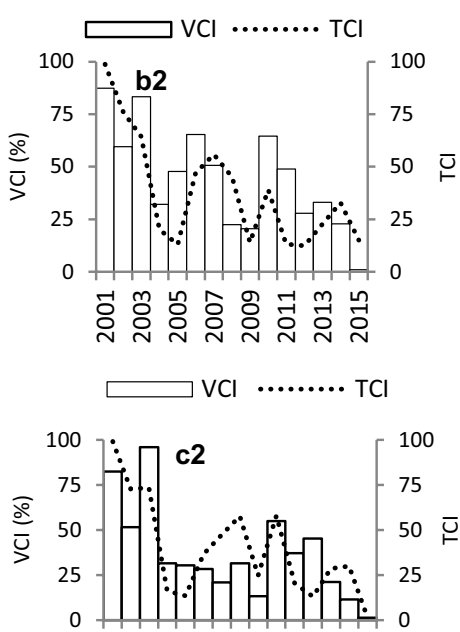

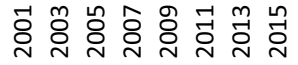
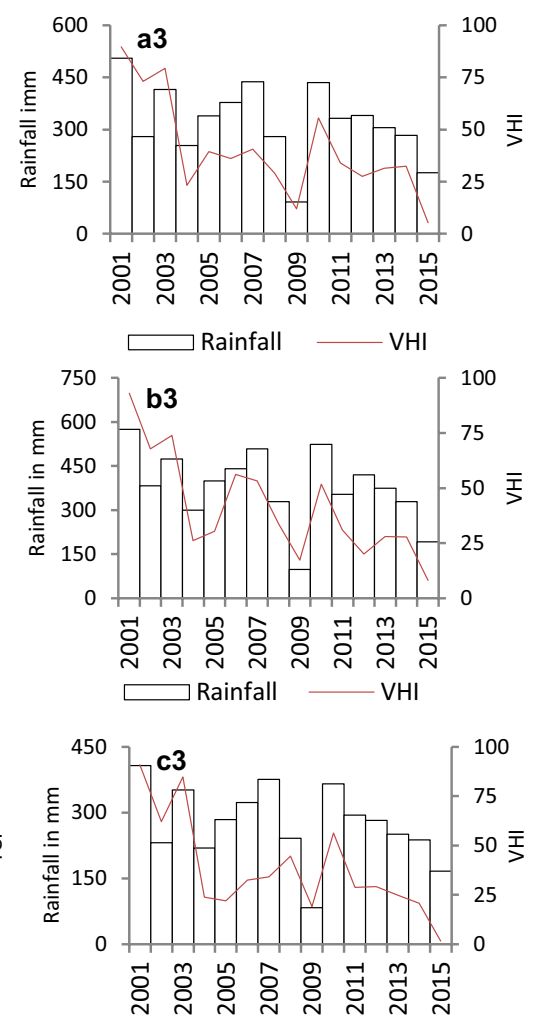

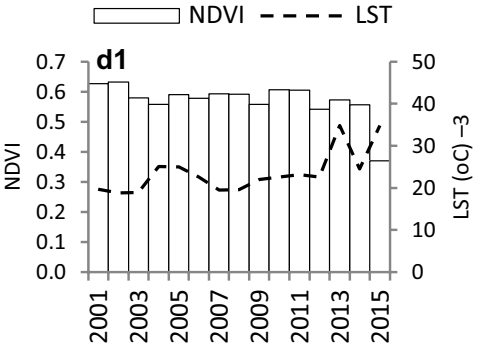

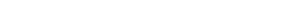

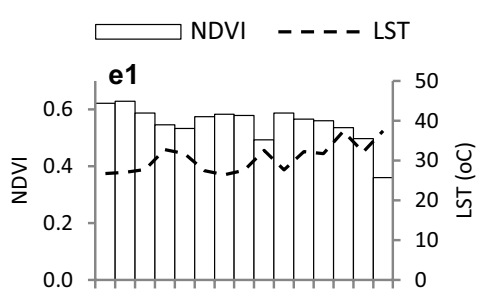

0.0 H1

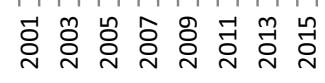

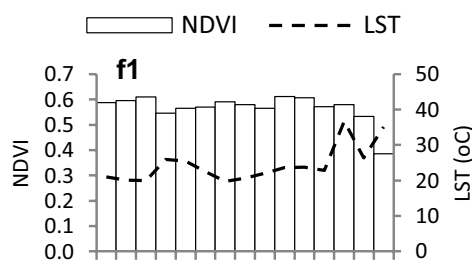

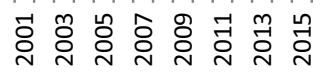

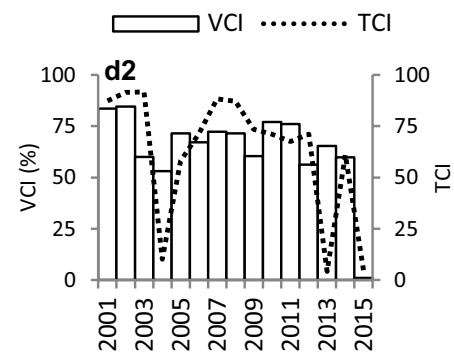

$\square \mathrm{VCl}$......... TCl

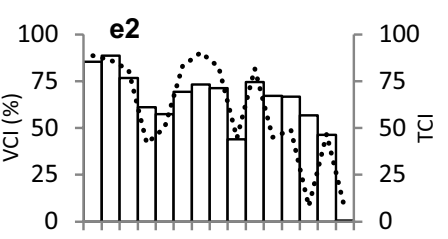

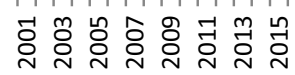
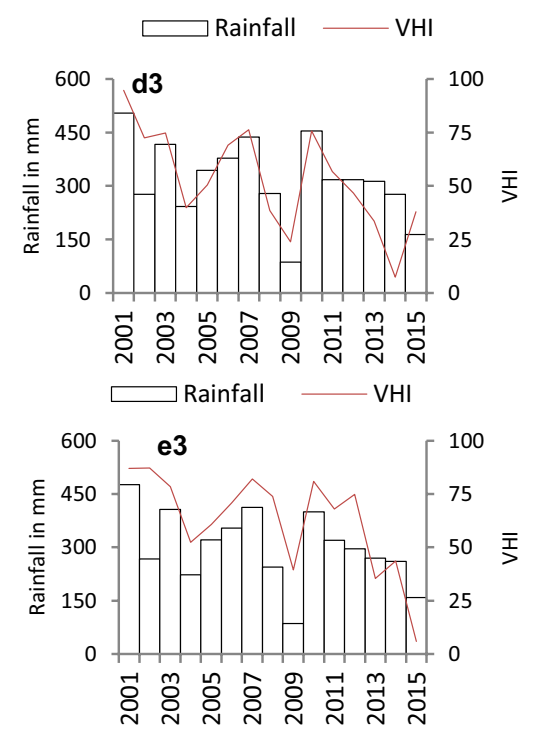

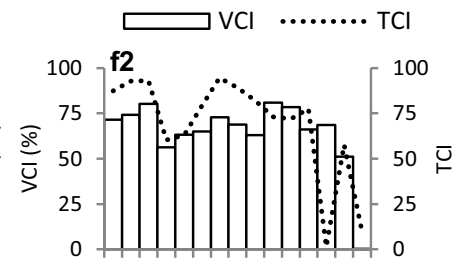

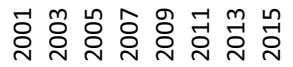

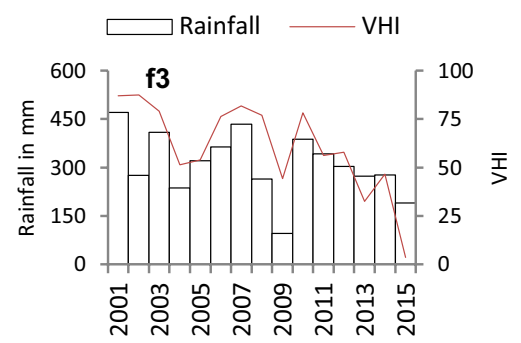

$\square$ NDVI - - - LST

$\square \mathrm{VCl} \cdots . . . . . \mathrm{TCl}$

$\square$ Rainfall $\longrightarrow$ VHI

Fig. 3 Multi-temporal trend of LST-NDVI, VCI-TCI, and VHI-rainfall 2001-2015. Lowlands area: a1-a3 Yalo, b1-b3 Megale, c1-c3 Gulina, Midlands area: d1-d3 Raya Azebo, e1-e3 Alamata, f1-f3 Kobo 


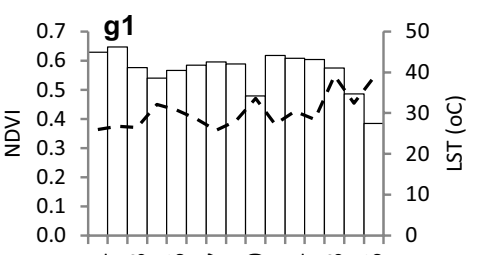

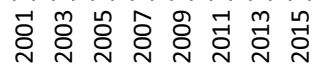
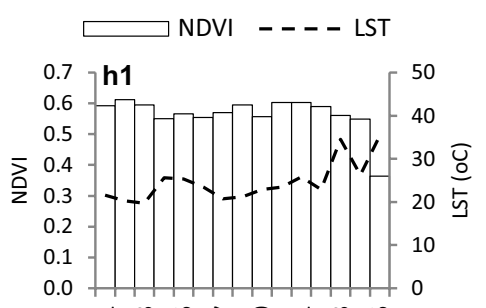

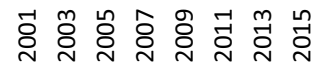
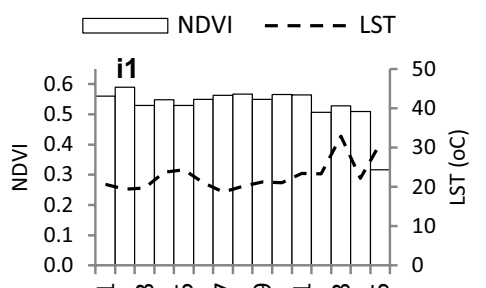

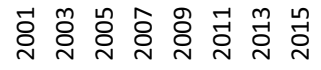

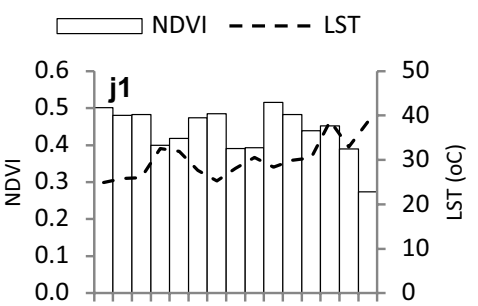

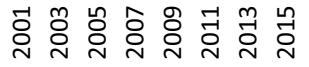
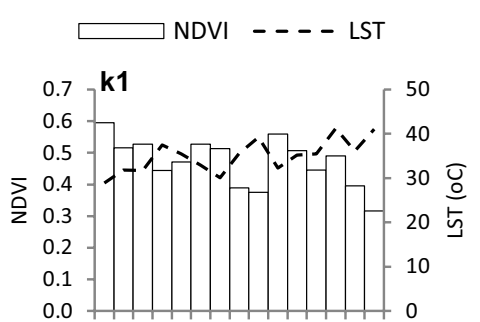

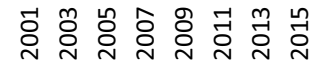

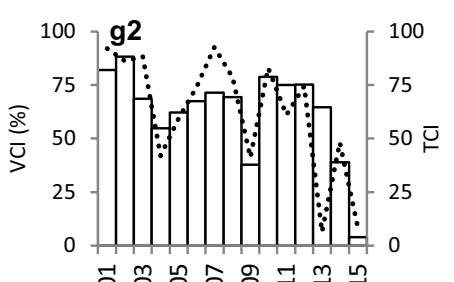

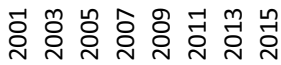

$\square \mathrm{VCl}$......... TCl

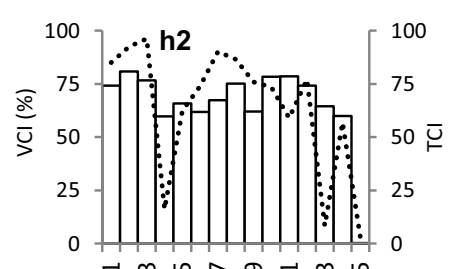

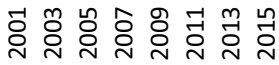

$\square \mathrm{VCl}$......... TCl

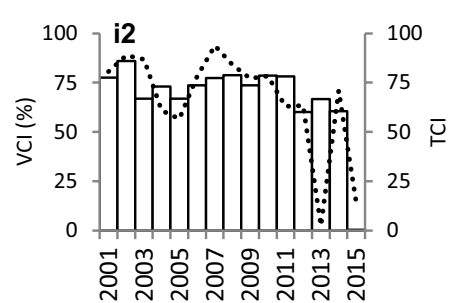

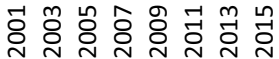

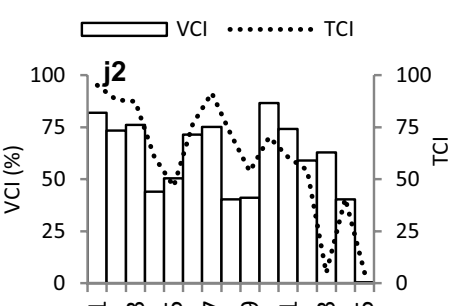

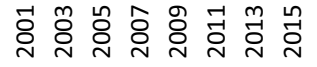

$\square \mathrm{VCl}$........ TCl

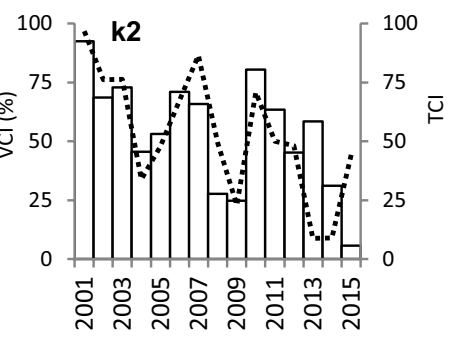

$\square \mathrm{VCl}$......... TCl
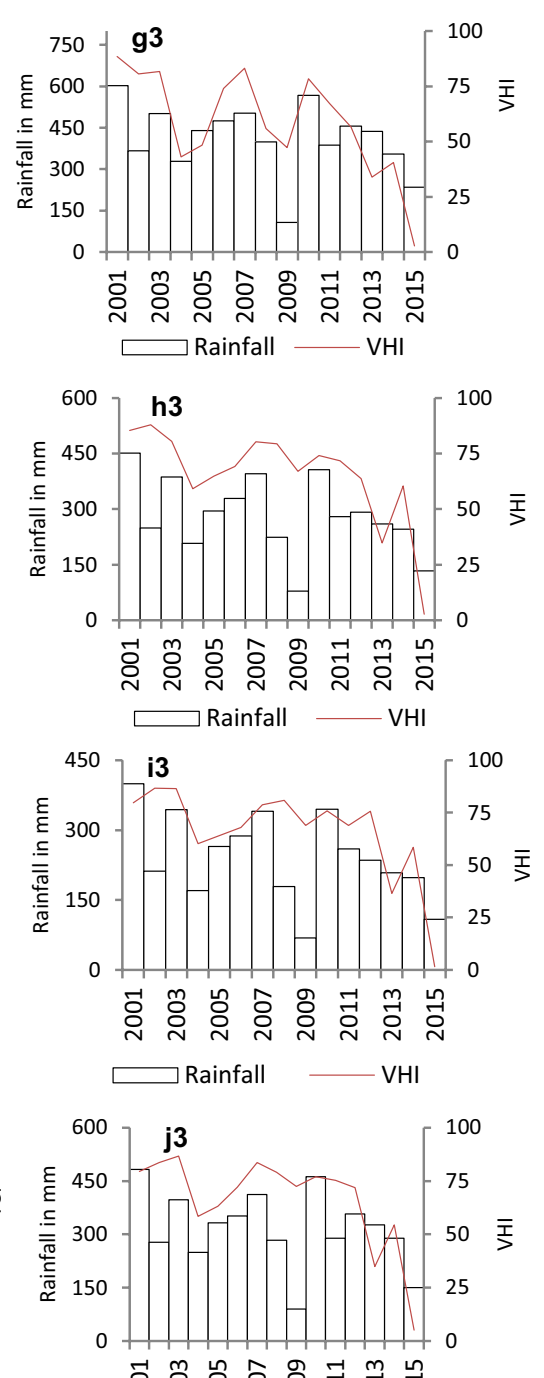

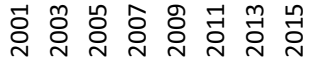
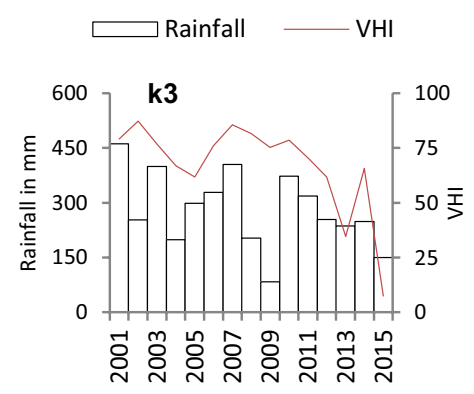

$\square$ Rainfall $\longrightarrow$ VHI

Fig. 4 Multi-temporal trend of LST-NDVI, VCI-TCI, and VHI—rainfall 2001-2015. Midlands area: $\mathbf{g 1 - g 3}$ HintaloWejirat, Highlands area: h1-h3 Endamehoni, i1-i3 Ofla, j1-j3 Alaje, k1-k3 Gidan 


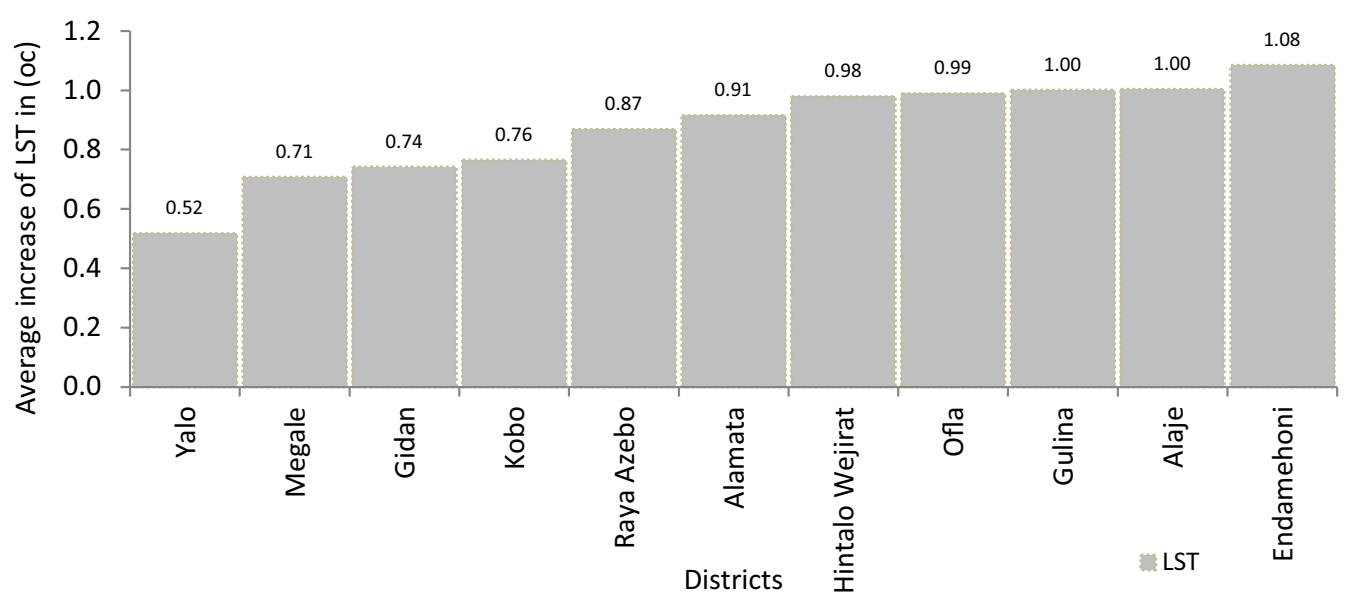

Fig. 5 Average increase of LST in all districts of the study area from the period 2001-2015

Table 2 Analysis of agricultural drought onset (0), cessation (C), duration (L), and recurrence interval (I) in the study area. Source: Gidey et al. (2017)

\begin{tabular}{lllll}
\hline District & O & C & L (year) & I \\
\hline Yalo and Gulina & 2004 & 2009 & 6 & 1.36 \\
Megale & 2011 & 2015 & 5 & \\
& 2004 & 2006 & 3 & 1.5 \\
Raya Azebo & 2008 & 2009 & 2 & \\
& 2011 & 2015 & 5 & \\
Alamata & 2004 & 2004 & 1 & 2.5 \\
Hintalo Wejirat & 2008 & 2009 & 1 & \\
Kobo, Endamehoni, Ofla, Alaje, Gidan & 2013 & 2015 & 3 & \\
& 2009 & 2009 & 1 & 3 \\
& 2013 & 2015 & 3 & \\
& 2015 & 2015 & 3 & 5 \\
& 2015 & 1 & 7.5 \\
\hline
\end{tabular}

5 years from 2011 to 2015. During these periods, significant effects on the livestock and humans were observed because the livelihoods of the communities are largely relying on the rearing of animals. Furthermore, the recurrence of agricultural drought in these two districts was once in every 1.36 years. Therefore, drought is a regular event in the area. Likewise, the rest of the study area was extensively affected by the agricultural drought. However, the impacts both on the livestock and on humans were diminishing due to the support of the federal and local governments and other non-government or humanitarian organizations. For example, the drought-affected communities were supported and are still getting food aid (Cereals and Other) at monthly basis as per the FAO survival threshold. In the study area, the government is supporting about 2131 kilo calorie (kcal) per person per day and also supply pasture and drinking water in the highly drought affected areas.

\section{Agro-ecological based frequency of agricultural drought incidence}

In this analysis, the VHI was considered as a basic parameter to declare the regularity of drought. Besides, the analyses were done based on the thresholds stated in Table 1. Kogan and Guo (2016) reported that the Horn of Africa (including the study area) was affected by droughts yearly. This study found that there are no districts that were free from the incidence of agricultural drought in the last 15 years. The highest agricultural drought incidence, which covers about $4409.7 \mathrm{~km}^{2}$, was observed in the lowland area. The frequency of agricultural drought event in these districts were 10-11 times in the last 15 years (Fig. 6). This means that drought is a regular event in the lowland area. The result is largely similar to what Kogan and Guo (2016) reported, but the return period is less in the highlands area (Fig. 6) and some parts of the midlands area. In the midland area (Raya Azebo, Alamata, Hintalo Wejirat, Kobo) the incidence is relatively lower and the area has been under the spell of drought for about 2-6 times covering about $6385 \mathrm{~km}^{2}$. However, in the highlands area, agricultural drought was occurred for about two times covering $3738 \mathrm{~km}^{2}$ in the last 15 years during the main rainy season. The return period of agricultural drought in this area is different due 


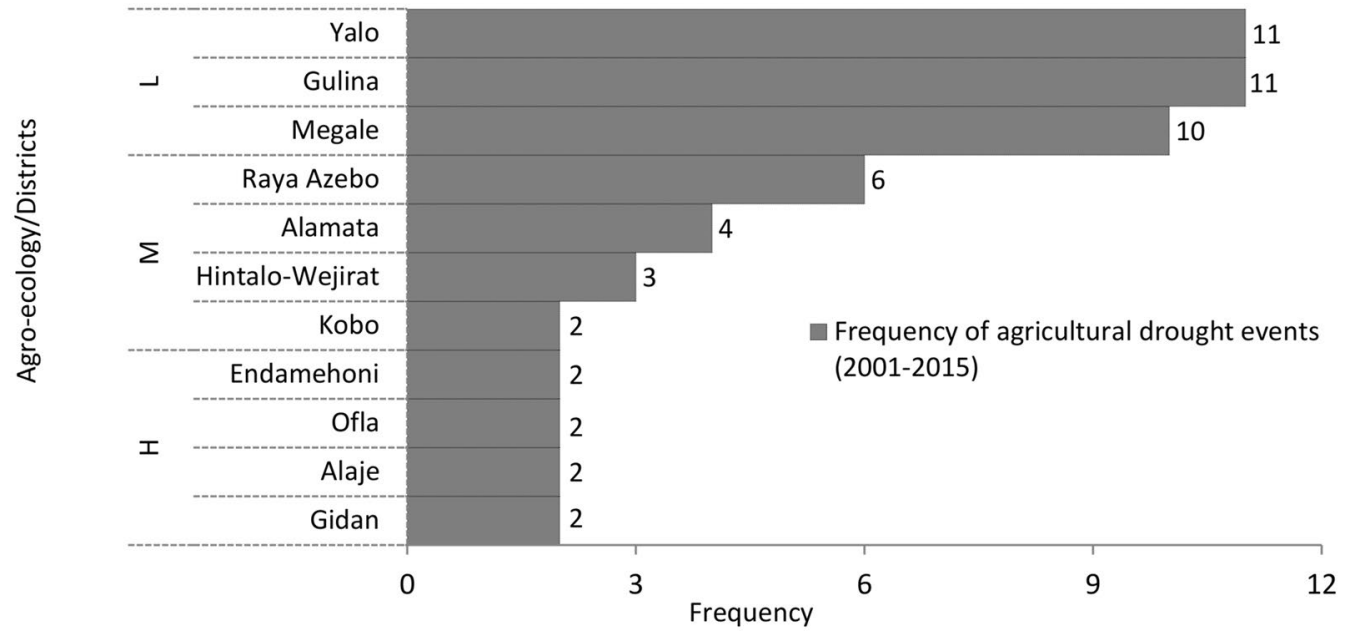

Fig. 6 Agro-ecological based frequency of agricultural drought incidence from 2001 to 2015. L lowlands, M midlands, H highlands

to the various levels of moisture stress, rainfall deficit, and Land Surface Temperature conditions.

\section{Analysis of the spatio-temporal agricultural drought}

Figure 7 shows that the study area was experiencing agricultural drought during the period 2001-2015. The year 2015 observed extreme drought period across the study area where the mean VHI value was less than 10 (Fig. 7). In this period, a catastrophic shortage of livestock forage, drinking water, and food occurred. Lei et al. (2016) suggested that exploring adaptation strategies to the expected increase in droughts incidence has become a critical issue of poverty reduction and agricultural sustainability. The impacts of drought can be reduced through involving the smalholder farmers and agro-pastoralists in a wide range of on- and off-farm practices.

\section{Coefficient of variation (CV) analysis}

Studies revealed that the coefficient of variation determined by the absolute dispersion of data relative to the mean and mainly expressed as a percentage. Analyzing the coefficient of variation is, therefore, useful to determine the statistical reliability and/or precision of estimation. The highest coefficient of variation depicting the greater level of dispersion, while the lowest value of the coefficient of variation corresponds to good precision. This study, therefore, found very high precision of estimation in all districts (Fig. 8). The overall coefficient of variation ranges from 6 to $20.7 \%$. Hence, a higher (20.7\%) degree of coefficient variation has reported in the districts of Hintalo Wejirat, and lower in Ofla (8.6\%). One of the possible reasons could be due to erratic rainfall distribution which increasing the seasonal rainfall variability among each district. This indicated that the coefficient of variation estimation was highly reliable as the maximum acceptable thresholds are below $29.9 \%$.

Agricultural drought (VHI) response to the seasonal rainfall This study found that the majority of the study area received below average seasonal rainfall, which can directly cause agricultural drought. The shortage of rainfall is thus the most important climatic constraint to the occurrence of agricultural drought. Figure 9 shows that how the agricultural drought (VHI) responded to the seasonal rainfall. Dutta et al. (2015) observed that a good agreement between the values of VCI and meteorological indices [e.g., Rainfall Anomaly Index (RAI)] and Yield Anomaly Index in India. Wan et al. (2004) found a linear correlation between Vegetation Temperature Condition Index (VTCI), and monthly precipitation in the southern Great Plains, USA. However, in this study, the relatively strong relationship between VHI and rainfall $\left(R^{2}=0.651\right.$, $\left.\mathrm{R}^{2}=0.602\right)$ at $p<0.01$ significance level in the districts of Megale (Fig. 9b), and Hintalo Wejirat (Fig. 9g) observed. Similarly, in the lowland area presented in Fig. 9 Yalo (b) and Gulina (c), an $\mathrm{R}^{2}=0.526$ and 0.463 was also observed. Likewise, in midlands area shown in Fig. 9d-f an $R^{2}$ of $0.596, R^{2}=0.544$, and $R^{2}=0.516$ were observed in the districts of Raya Azebo, Alamata, and Kobo. Furthermore, in the highland area depicted under Fig. $9 \mathrm{~h}-\mathrm{k}$ an $R^{2}=0.411$, an $R^{2}=0.383, R^{2}=0.398$, and $R^{2}=0.357$ was observed. However, in these area, the slightly poor 


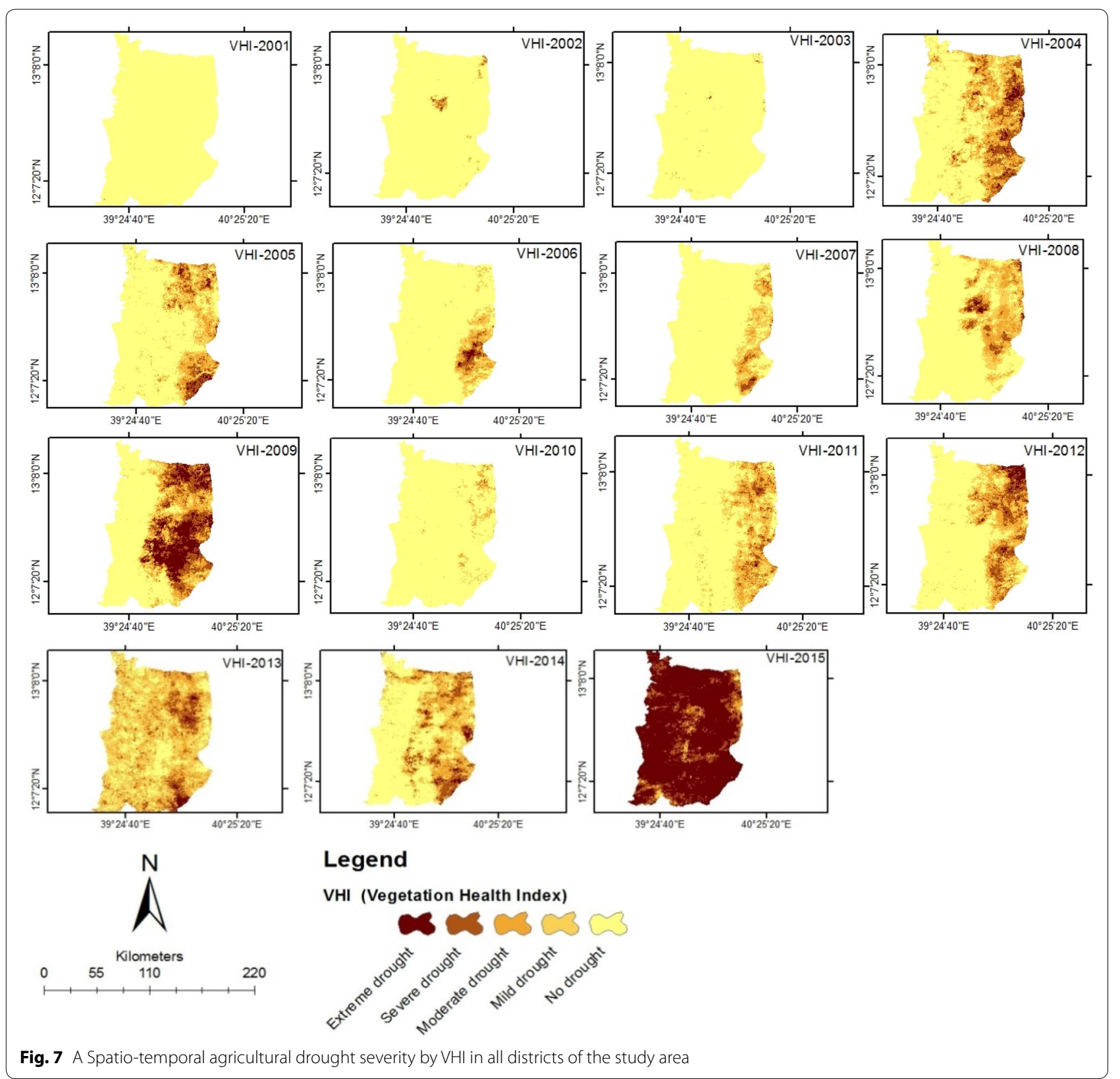

regression result was associated with several factors such as topography. The relationship between $\mathrm{VHI}$ and rainfall is statistically significant at $(p<0.01$ and $p<0.05)$ across all districts of the study area. Moreover, the regression analysis results of this study indicated that agricultural drought (VHI) positively responded to rainfall. This reveals that when rainfall increases, VHI also tends to increase. As a result, agricultural drought incidences significantly diminished. This study also demonstrated that the incident of agricultural drought was due to shortage of rainfall leading to high level of moisture stress. 


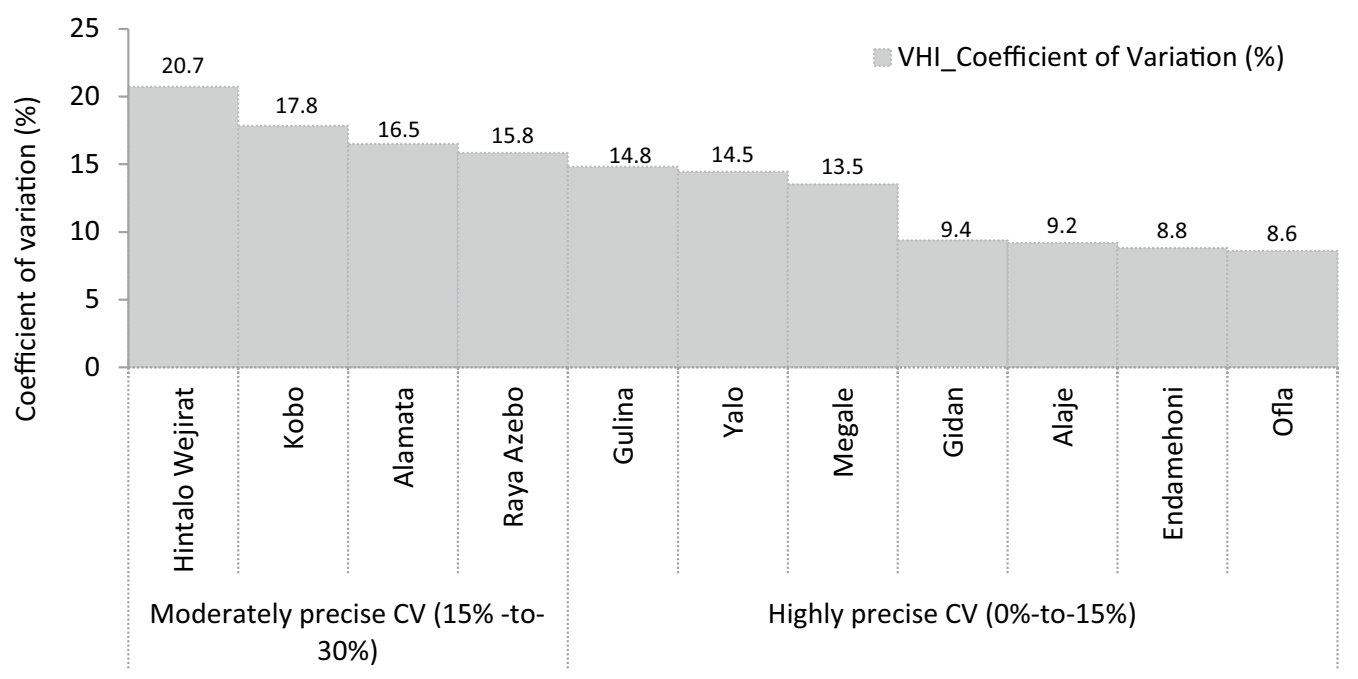

Fig. 8 Coefficient of variation (CV) precision in percent for the period of 2001-2015

\section{Conclusions}

Remote sensing and GIS-based agricultural drought can be better monitored by VHI composed of VCI and TCI drought indices. This study analyzed the onset, cessation, duration, recurrence interval, frequency, severity and spatial extent of agricultural drought using VHI at 3 -month time-scale during the main rainy season. NDVI value was extremely low in the lowland area than the mid and highlands area. NDVI coverage during the main rainy season decreased by $3-4 \%$ in all districts of the study area. However, LST showed a significant increase by $0.52-1.08{ }^{\circ} \mathrm{C}$ across all agro-ecologies as well as districts in the last 15 years. LST was high both in the lowland and midlands area and it is an unfavorable condition for the vegetation because it causes stress, while the lowest LST is largely a favorable condition. The increase in LST and the decrease in NDVI may contribute considerable moisture stress that can trigger the incidences of agricultural drought. Furthermore, the VHI and rainfall value diminished significantly during the main rainy season. This revealed that the incidence of agricultural drought became more frequent and severe, particularly in lowland and some parts of the mid and highlands area. There were no districts that were free from the incidence of agricultural drought during the study periods. A high frequency of agricultural drought incidence (10-11 times) was observed in the lowland of the study area consisting of Yalo, Megale, and Gulina districts. The incidence is relatively lower (2-6 times) in the midland area (Raya Azebo, Alamata, Hintalo Wejirat, Kobo). Furthermore, the study noted that the frequency of drought was very low in the highlands (Endamehoni, Ofla, Alaje, and Gidan) of the area. Both the lowland and midlands area were more exposed to the agricultural drought than the highland area. VHI model showed that the year 2015 was extremely drought period across the study area where the mean VHI value was less than ten. The overall coefficient of variation ranged from 6 to $20.7 \%$. A higher (20.7\%) coefficient variation was observed in Hintalo Wejirat, and lower in Ofla (8.6\%). The relationship between rainfall and VHI is positive $\left(R^{2}=0.357\right.$ to $\left.R^{2}=0.651\right)$ and statistically significant at $(p<0.01$ and $p<0.05)$ across all districts of the study area. This relationship reveals that when rainfall increases, VHI also tends to increase. As a result, agricultural drought incidences significantly reduced. This study suggests that the effect of drought could be reduced through involving the smallholder farmers in a wide range of on- and off-farm practices. 


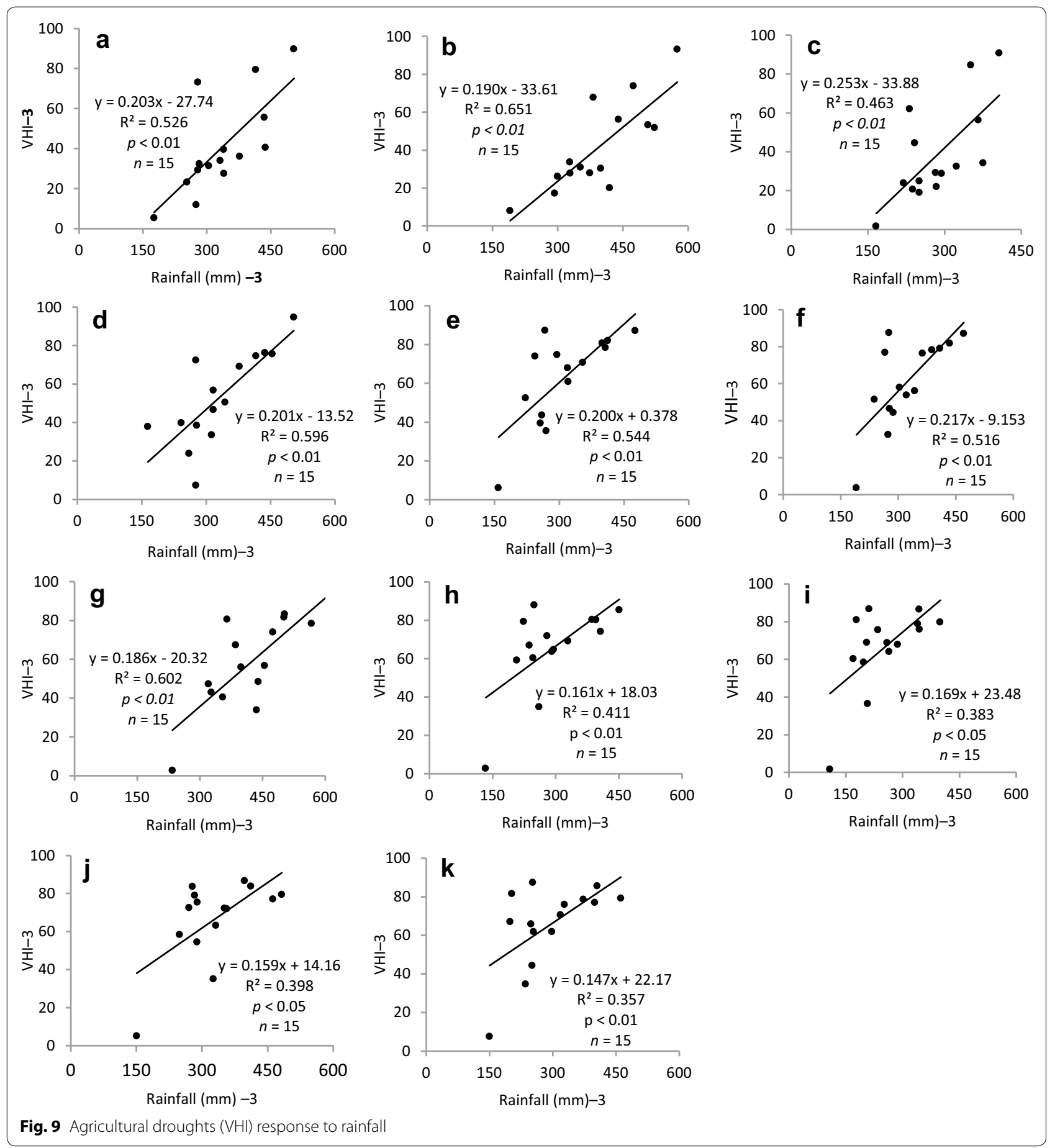

The study may also support formulation and implementation of drought coping and mitigation programs in the study area.

\section{Abbreviations}

CV: Coefficient of Variation; LST: Land Surface Temperature; NDVI: Normalized Difference Vegetation Index; TCI: Temperature Condition Index; VCI: Vegetation Condition Index; VHI: Vegetation Health Index. 


\section{Authors' contributions}

EG initiate the research idea, review relevant literature, design scientific methods, field data collection, data cleaning, data analysis and interpretation, prepare draft manuscripts for publication. OD, RS, ES, and AZ evaluate the research idea, supervise the overall research activities, and enrich the manuscript. All authors have contributed their well-grounded knowledge to the project. All authors read and approved the final manuscript.

\section{Author details}

${ }^{1}$ Department of Environmental Science, University of Botswana, Private Bag UB 0704, Gaborone, Botswana. ${ }^{2}$ Land Resource Management and Environmental Protection, Mekelle University, P.O. Box 231, Mekelle, Ethiopia. ${ }^{3}$ Institute of Climate and Society, Mekelle University, P.O. Box 231, Mekelle, Ethiopia.

\section{Acknowledgements}

The authors thank financial support of Mekelle University and Open Society Foundation-Africa Climate Change Adaptation Initiative (OSF-ACCAI) project of Mekelle University-Ethiopia. The lead author is grateful for the Ph.D. scholarship given by the Transdisciplinary Training for Resource Efficiency and Climate Change Adaptation in Africa (TreccAfrica II) project. The authors would also like to thank the National Aeronautics and Space Administration (NASA)_-United States Geological Survey (USGS) and Famine Early Warning System Network (FEWS-NET) for the provision of satellite data. We are grateful for the constructive feedback of the two anonymous reviewers and the editor.

\section{Competing interests}

The authors declare that they have no competing interests.

\section{Consent for publication}

All authors thoroughly read the manuscript and agree for publication.

\section{Ethics approval and consent to participate}

This research paper is part of our own project entitled "Analysis of the longterm agricultural drought onset, cessation, duration, frequency, severity and its spatial extents using the Vegetation Health Index (VHI) in Raya and its environs, Northern Ethiopia". Therefore, there is no any ethical conflict and all authors authorize to publish the findings.

\section{Funding}

This research was financially supported by Mekelle University under Grant Number CRPO/ICS/PhD/001/09 and the Open Society Foundation-Africa Climate Change Adaptation Initiative (OSF-ACCAI) project of Mekelle University.

\section{Publisher's Note}

Springer Nature remains neutral with regard to jurisdictional claims in published maps and institutional affiliations.

Received: 13 February 2018 Accepted: 19 May 2018

Published online: 05 June 2018

\section{References}

Alemaw BF, Simalenga T (2015) Climate change impacts and adaptation in rainfed farming systems: a modeling framework for scaling-out climate smart agriculture in Sub-Saharan Africa. Am J Clim Change 4(04):313

Ayenew T, GebreEgziabher M, Kebede S, Mamo S (2013) Integrated assessment of hydrogeology and water quality for groundwater-based irrigation development in the Raya Valley, northern Ethiopia. Water Int 38(4):480-492

Barbosa HA, Huete AR, Baethgen WE (2006) A 20-year study of NDVI variability over the Northeast Region of Brazil. J Arid Environ 67(2):288-307

Bhuiyan C (2004) Various drought indices for monitoring drought condition in Aravalli terrain of India. In: Proceedings of the XXth ISPRS Congress, Istanbul, Turkey, pp 12-23

Bhuiyan C (2008) Desert vegetation during droughts: response and sensitivity. Int Arch Photogramm Remote Sens Spat Inf Sci 21:907-912
Bhuiyan C, Singh RP, Kogan FN (2006) Monitoring drought dynamics in the Aravalli region (India) using different indices based on ground and remote sensing data. Int J Appl Earth Obs Geoinf 8(4):289-302

Brown JF, Howard D, Wylie B, Frieze A, Ji L, Gacke C (2015) Application-ready expedited MODIS data for operational land surface monitoring of vegetation condition. Remote Sens 7(12):16226-16240

Choi M, Jacobs JM, Anderson MC, Bosch DD (2013) Evaluation of drought indices via remotely sensed data with hydrological variables. J Hydrol 476:265-273

Dutta D, Kundu A, Patel NR, Saha SK, Siddiqui AR (2015) Assessment of agricultural drought in Rajasthan (India) using remote sensing derived Vegetation Condition Index (VCl) and Standardized Precipitation Index (SPI). Egyptian J Remote Sens Space Sci 18(1):53-63

Frey CM, Kuenzer C, Dech S (2012) Quantitative comparison of the operational NOAA-AVHRR LST product of DLR and the MODIS LST product V005. Int J Remote Sens 33(22):7165-7183

Gidey E, Dikinya O, Sebego R, Segosebe E, Zenebe A (2017) Modeling the Spatio-temporal dynamics and evolution of land use and land cover (1984-2015) using remote sensing and GIS in Raya, Northern Ethiopia. Model Earth Syst Environ 3(4):1285-1301

Gu Y, Brown JF, Verdin JP, Wardlow B (2007) A five-year analysis of MODIS NDVI and NDWI for grassland drought assessment over the central Great Plains of the United States. Geophys Res Lett. https://doi.org/10.1029/2006G L029127

Jain SK, Keshri R, Goswami A, Sarkar A, Chaudhry A (2009) Identification of drought-vulnerable area using NOAA AVHRR data. Int J Remote Sens 30(10):2653-2668

Jenkerson CB, Schmidt GL (2008) eMODIS product access for large scale monitoring. In: Proceedings of the 17th William T. Pecora Memorial Symposium on Remote Sensing, Denver, CO

Jenkerson C, Maiersperger T, Schmidt G (2010) eMODIS: a user-friendly data source (No. 2010-1055). US Geological Survey

Karnieli A, Bayasgalan M, Bayarjargal Y, Agam N, Khudulmur S, Tucker CJ (2006) Comments on the use of the vegetation health index over Mongolia. Int J Remote Sens 27(10):2017-2024

Karnieli A, Agam N, Pinker RT, Anderson M, Imhoff ML, Gutman GG, Goldberg A (2010) Use of NDVI and land surface temperature for drought assessment: merits and limitations. J Clim 23(3):618-633

Kogan FN (1990) Remote sensing of weather impacts on vegetation in nonhomogeneousarea. Int J Remote Sens 11(8):1405-1419

Kogan FN (1995) Application of vegetation index and brightness temperature for drought detection. Adv Space Res 15(11):91-100

Kogan FN (2000) Contribution of remote sensing to drought early warning. In: Wilhite DA, Sivakumar MVK, Wood DA (eds) Early warning systems for drought preparedness and drought management. Proceedings of an Expert Group Meeting held 5-7 September, 2000, in Lisbon, Portugal, vol 57. World Meteorological Organization, Geneva, pp 86-100

Kogan FN (2001) Operational space technology for global vegetation assessment. Bull Am Meteor Soc 82(9):1949

Kogan F, Guo W (2016) Early twenty-first-century droughts during the warmest climate. Geomatics Nat Hazards Risk 7(1):127-137

Kogan F, Adamenko T, Guo W (2013) Global and regional drought dynamics in the climate warming era. Remote Sens Lett 4(4):36472

Kogan F, Guo W, Strashnaia A, Kleshenko A, Chub O, Virchenko O (2016) Modelling and prediction of crop losses from NOAA polar-orbiting operational satellites. Geomatics Nat Hazards Risk 7(3):886-900

Lei Y, Liu C, Zhang L, Luo S (2016) How smallholder farmers adapt to agricultural drought in a changing climate: a case study in southern China. Land Use Policy 55:300-308

Liu WT, Kogan FN (1996) Monitoring regional drought using the vegetation condition index. Int J Remote Sens 17(14):2761-2782

Marufah U, Hidayat R, Prasasti I (2017) Analysis of relationship between meteorological and agricultural drought using standardized precipitation index and vegetation health index. In: IOP Conference Series: Earth and Environmental Science, vol 54, No. 1. IOP Publishing, Bristol. p 012008

Maybank J, Bonsai B, Jones K, Lawford R, O'brien EG, Ripley EA, Wheaton E (1995) Drought as a natural disaster. Atmos Ocean 33(2):195-222

Mishra AK, Singh VP (2011) Drought modeling - a review. J Hydro 403(1):157-175 
Owrangi MA, Adamowski J, Rahnemaei M, Mohammadzadeh A, Sharifan RA (2011) Drought monitoring methodology based on AVHRR images and SPOT vegetation maps. J Water Resour Protect 3(05):325

Parviz L (2016) Determination of effective indices in the drought monitoring through analysis of satellite images. Agric Forest Poljoprivreda i Sumarstvo 62(1):305-324

Peters AJ, Walter-Shea EA, Ji L, Vina A, Hayes M, Svoboda MD (2002) Drought monitoring with NDVI-based standardized vegetation index. Photogram Eng Remote Sens 68(1):71-75

Raya Valley Livelihood Zone (2007) Livelihood profile Tigray Region, Ethiopia. pp 1-5. http://www.dppc.gov.et/Livelihoods/Tigray/Pages/RVL_LZ.htm. Accessed 19 May 2017

Rhee J, Im J, Carbone GJ (2010) Monitoring agricultural drought for arid and humid regions using multi-sensor remote sensing data. Remote Sens Environ 114(12):2875-2887

Se AST, Dorosh P, Gemessa SA (2011) Crop production in Ethiopia: regional patterns and trends. Food Agric Ethiopia Prog Policy Chall 74:53

Segosebe EM (1990) Some reflections on the concept of critical herdsize and its relevance to drought-prone Botswana. Botswana Notes Records 22:105-112

Seiler RA, Kogan F, Sullivan J (1998) AVHRR-based vegetation and temperature condition indices for drought detection in Argentina. Adv Space Res 21(3):481-484

Sholihah RI, Trisasongko BH, Shiddiq D, La Ode SI, Kusdaryanto S, Panuju DR (2016) Identification of agricultural drought extent based on vegetation health indices of landsat data: case of Subang and Karawang, Indonesia. Proc Environ Sci 33:14-20

Singh RP, Roy S, Kogan F (2003) Vegetation and temperature condition indices from NOAA AVHRR data for drought monitoring over India. Int J Remote Sens 24(22):4393-4402

Song X, Saito G, Kodama M, Sawada H (2004) Early detection system of drought in East Asia using NDVI from NOAA/AVHRR data. Int J Remote Sens 25(16):3105111

Sruthi S, Aslam MM (2015) Agricultural drought analysis using the NDVI and landsurface temperature data; a case study of Raichur district. Aquat Proc $4: 1258-1264$
Swets DL (1999) A weighted least-squares approach to temporal smoothing of NDVI. In: Proceedings of the 1999 ASPRS annual conference, from image to information. Portland. American society for photogrammetry and remote sensing, Bethesda, 17-21 May 1999

Tsiros E, Domenikiotis C, Spiliotopoulos M, Dalezios NR (2004) Use of NOAA/ AVHRR-based vegetation condition index (VCI) and temperature condition index (TCI) for drought monitoring in Thessaly, Greece. In: EWRA Symposium on water resources management: risks and challenges for the 21st century, Izmir, Turkey, pp 2-4

Umran Komuscu A (1999) Using the SPI to analyze spatial and temporal patterns of drought in Turkey. In: Drought Network News (1994-2001), vol 11, issue 1. Drought - National Drought Mitigation Center, DigitalCommons@University of Nebraska - Lincoln, University of Nebraska - Lincoln, pp 7-13

Van Hoolst R, Eerens H, Haesen D, Royer A, Bydekerke L, Rojas O, Racionzer P (2016) FAO's AVHRR-based Agricultural Stress Index System (ASIS) for global drought monitoring. Int J Remote Sens 37(2):418-439

Vicente-Serrano SM, Beguería S, Gimeno L, Eklundh L, Giuliani G, Weston D, Konte D (2012) Challenges for drought mitigation in Africa: the potential use of geospatial data and drought information systems. Appl Geogr 34:471-486

Wan Z (2006) MODIS land surface temperature products users'quide. SantaBarbara, Institute forComputational Earth System Science, University of California

Wan Z, Wang P, Li X (2004) Using MODIS land surface temperature and normalized difference vegetation index products for monitoring drought in the southern Great Plains, USA. Int J Remote Sens 25(1):61-72

Wilhite DA, Glantz MH (1985) Understanding: the drought phenomenon: the role of definitions. Water Int 10(3):111-120

Zhang J, Mu Q, Huang J (2016) Assessing the remotely sensed Drought Severity Index for agricultural drought monitoring and impact analysis in North China. Ecol Ind 63:29609

Zhang L, Jiao W, Zhang H, Huang C, Tong Q (2017) Studying drought phenomena in the Continental United States in 2011 and 2012 using various drought indices. Remote Sens Environ 190:96-106

\section{Submit your manuscript to a SpringerOpen ${ }^{\circ}$ journal and benefit from:}

- Convenient online submission

- Rigorous peer review

- Open access: articles freely available online

- High visibility within the field

- Retaining the copyright to your article

Submit your next manuscript at $\boldsymbol{\nabla}$ springeropen.com 